\title{
COVID-19:
}

\section{Are you prepared for the next emerging disease?}

\author{
Natasha Salt BSc, BASc, CPHI(C), CIC \\ Sunnybrook Health Sciences Centre, Toronto, ON, Canada \\ natasha.salt@sunnybrook.ca
}

The role of an infection control preventionist (ICP) has never been as diverse as it is today. While ICPs have been involved in emergency management since the 1990s, a formal role was first conceived in 2005 when an all-hazards approach was embraced by the Association for Professionals in Infection Control and Epidemiology [1]. ICPs play an important role in emergency preparedness and management for: emerging diseases, pandemics, bioterrorism attacks, natural disasters and manmade mass casualties. The SARS-CoV-2 outbreak in China has provided a burning platform for activating internal incident management systems (IMS), enhancing cross-sector planning, re-examining existing pandemic plans, optimizing communication pathways, and gearing up resources and training with ICPs leading the incident command.

Collaborating with Emergency Preparedness/Management $(\mathrm{EP} / \mathrm{M})$ is vital to responding to emerging diseases. Through established processes, they are involved in activating the IMS, which can direct important resources to the planning table. The IMS structure provides a standardized organizational response that uses common functions, processes and terminology consistent throughout all partners in the healthcare system [2]. Once the Health Emergency Operations Centre (HEOC) is activated, stakeholders such as communications, occupational health and safety, logistics, operations, finance/administrative and planning can be added as needed since the system is modular and adaptable to current needs. Regular structured meetings with definitive action items improve accountabilities and prioritize needs.

In Ontario, the severe acute respiratory syndrome (SARS) commission report revealed that the health system was working in silos [3]. Collaboration and clear communication during crisis are imperative to an effective response. Hospitals must reach out to their partners to ensure a consistent and evidence-based approach to implementing infection control strategies. In addition, sharing resources not only promotes consistency but also strengthens the entire system so that response efforts are distributed and local planning can be accelerated. Leaders must leverage technology such as webinars, GoToMeeting ${ }^{\mathrm{TM}}$ or teleconferencing to connect frequently and discuss operational opportunities and challenges they are facing.

Internal communication must also be clear and transparent. The SARS commission report identified weaknesses in internal collaboration between staff, infection prevention and control, occupational health and safety $(\mathrm{OH} \& \mathrm{~S})$ and the Ministry of Labour [3]. These networks should now be clearly developed and optimized during an emerging disease response. Providing resources via a centralized repository supports transparency and provides staff with a mechanism to connect with leadership to vocalize their questions. Additionally, ICPs should be well equipped with resources and education to support dissemination on patient care units. Redundancies to support this communication should also be considered by leveraging stakeholders such as EP/M and $\mathrm{OH} \& \mathrm{~S}$ who can support a protracted response. Mechanisms to keep everyone abreast of the situation must be established early and plans to ensure their continuity should be considered.

An emerging disease is an opportunity to review existing pandemic, surge and business continuity plans. Though an established frequency to review these plans should be in place, it offers the leadership team an opportunity to review these plans to ensure they meet the needs of the organization and its partners at the time of the event. Supported by the IMS, it offers the team a chance to mobilize and prioritize resources in order to support response efforts. Issues in areas such as logistics may be apparent in the early stages of an emerging disease where access to appropriate personal protective equipment is limited due to escalating fear, hoarding and theft. Identifying strategies to mitigate shortages may require immediate implementation in order to prepare for events ahead. Updating plans to current realities will help to inform management strategies as well as inform future planning.

While the SARS-CoV-2 is an emerging pathogen that requires our immediate attention, it is important to not lose sight of the 
fact that emergencies take shape in many forms. ICPs must be active members of the EP/M steering committees and help support planning efforts for all hazards. Participation in tabletop exercises, live exercises and real events help to inform afteraction reports, which highlight lessons learned and opportunities for improvement. Infection prevention and control matters and has a role during all emergencies [4]. These routine efforts will help support an ICP's role in EP/M making a crisis more manageable when it presents itself.

Emerging diseases and pandemics pose the most significant threat to morbidity and mortality $[1,4]$. Engaging, developing and maintaining partnerships early, supports consistency in management, role clarification and communication. EP/M teams are catalysts that should be not only be leveraged during an emergency, but also in the preparedness phases of planning.

\section{REFERENCES}

1. Rebmann, T., Wagner, W., \& Warye, K. (2009). APIC's role in emergency management: Proceedings of the 2008 APIC Emergency Preparedness Mini-Summit. American Journal of Infection Control, 37(4), 343-348. https://0-doi org.aupac. lib.athabascau.ca/10.1016/j.ajic.2008.11.012

2. Ontario Ministry of the Solicitor General. (2017). Incident management system. Retrieved from https://www.emergencymanagementontario.ca/english/ emcommunity/ProvincialPrograms/IMS/ims_main.html

3. Ontario \& Campbell, A. G. (2006). Spring of fear: The SARS Commission final report. Toronto: SARS Commission.

4. Rebmann, T. (2009). APIC State-of-the-Art Report: The role of the infection preventionist in emergency management. American Journal of Infection Control, 37(4), 271-281. https://0-doi-org.aupac.lib.athabascau.ca/10.1016/ j.ajic.2008.12.002

\section{Hand Sanitizing Perfection}

\section{- The Original Hand Sanitizing Station \\ - Increases Efficacy of Your Hygiene Supplies \\ - Eliminates Flimsy Drip Catches \\ - Prevents Facility Damage \\ - Ergonomic \& Accessible Design \\ - Many Configurations \& Uses}

Cleaning hands across Canada since 2005. Made in Canada. Built-to-order.

\section{tagg CLEANDHANDS ${ }^{\circledR}$ taggcleanhands.com Draw Attention, Educate \& Dispense.

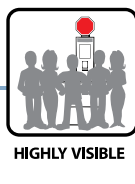

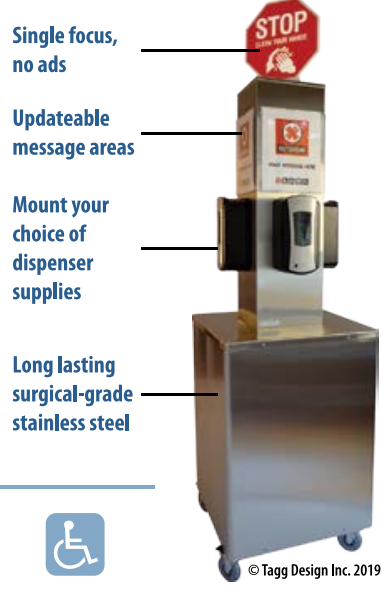

